\section{Peribiliary cysts: a systematic review and proposal of a classification framework}

To cite: Bazerbachi F, Haffar S, Sugihara T, et al. Peribiliary cysts: a systematic review and proposal of a classification framework. BMJ Open Gastro 2018;5:e000204. doi:10.1136/ bmjgast-2018-000204

- Additional material is published online only. To view, please visit the journal online (http://dx.doi.org/10.1136/ bmjgast-2018-000204).

FB and SH contributed equally.

Received 1 March 2018 Revised 29 March 2018 Accepted 10 April 2018

\section{Check for updates}

${ }^{1}$ Department of

Gastroenterology and Hepatology, Mayo Clinic Rochester, Minnesota, USA ${ }^{2}$ Digestive Center for Diagnosis and Treatment, Damascus, Syria

${ }^{3}$ Division of Medicine and Clinical Science, Department of Multidisciplinary Internal Medicine, Tottori University, Tottori, Japan

${ }^{4}$ Department of Laboratory Medicine and Pathology, Mayo Clinic, Rochester, Minnesota, USA

${ }^{5}$ Department of Radiology, Mayo Clinic, Rochester, Minnesota, USA

${ }^{6}$ Evidence-based Practice Center, Robert D and Patricia E Kern Center for the Science of Health Care Delivery, Mayo Clinic, Rochester, Minnesota, USA

Correspondence to Dr Barham K Abu Dayyeh; AbuDayyeh.Barham@mayo.edu

\section{ABSTRACT}

Objective Peribiliary cysts are usually benign, although severe complications and mortality may occur, and they may be confounded with other diseases. No classification delineating their different characteristics exists.

Design We performed a systematic review of the frequency and clinical manifestations of peribiliary cysts. Two reviewers identified studies after searching multiple databases on 2 August 2017.

Results These cysts were prevalent in cirrhosis $(9 \%)$. A total of 135 patients were reported in 72 papers with sufficient clinical data (10 countries, 65\% from Japan, median age 63 years (range: 4-88), and 80\% were males). Symptoms were present in $70 \%$. Misdiagnosis occurred in $40 \%$, and $33 \%$ underwent therapeutic misadventures. Cysts were solitary in $10 \%$. Obstructive features and cholangitis were observed in $36 \%$ and $12.5 \%$, respectively. Cysts progression was observed in $37.5 \%$ over a median of 18 months. Mortality was $24 \%$, mostly due to cirrhosis. A classification framework is proposed, wherein type I includes hepatic, type II extrahepatic and type III mixed hepatic and extrahepatic cysts, each having distinct features. Specifically, type II was more frequent in females, solitary, without cirrhosis, presenting with obstructive jaundice, more difficult to diagnose and required more surgical interventions (all $\mathrm{p}<0.05$ ).

Conclusion Although rarely studied in the literature, peribiliary cysts were frequent in studies designed to evaluate their prevalence, and were mostly asymptomatic. Inaccurate diagnosis, therapeutic misadventures, cysts progression and cysts-related complications are frequent. In a novel classification framework based on location, extrahepatic peribiliary cysts have distinct characteristics and require a special approach for diagnosis and management.

\section{BACKGROUND}

Peribiliary cysts are one of the most recent discoveries in the domain of liver cystic abnormalities. These lesions are usually found up the liver hilum, tracking the fourthorder biliary duct branches. Although they are usually diminutive, measuring $<20 \mathrm{~mm}$ in diameter and lacking communication with the adjoining large bile ducts, they can at times cluster together resembling a multilocular malignancy, mimic biliary dilation (taking the appearance of periportal fluid-filled cylinders), or grow to compress the neighbouring structures, resulting in obstruction and cholestasis. These structures do not communicate with the biliary lumen, and are external to the duct walls. Although these cysts are usually benign, and typically found in patients with liver cirrhosis, they can occasionally cause biliary obstruction or cholangitis. The clinical importance of these structures arises from the fact that they may mimic other diseases (eg, cholangiocarcinoma, choledochal cyst), or may represent a harbinger of an important underlying illness (eg, portal hypertension), which may lead the clinician to unneeded investigations. ${ }^{12}$ Our aim was to systematically review the characteristics of these anatomical variants, and propose a clinical classification based on their location.

\section{METHODS}

This systematic review is reported in line with the guidelines of the preferred reporting items for systematic reviews and meta-analyses with an a priori study protocol (see online supplement 1 ).

\section{Data sources and search strategies}

A comprehensive search of several databases from each database's inception to 2 August 2017, any language was conducted. The actual strategy is provided in online supplements 2 and 3. In addition, the first 300 entries of Google Scholar were searched using the terms 'peribiliary cysts' to look for studies not included in major databases. Reference lists were manually reviewed for additional publications. 


\section{Inclusions criteria}

Inclusion criteria was based on a priori definitions of the frequency, diagnostic modality and clinical manifestations of peribiliary cysts (see online supplement 3 ).

\section{Exclusion criteria}

We excluded duplicated studies and studies with insufficient clinical data.

\section{Data extraction and assessment}

Two independent reviewers $(\mathrm{SH}, \mathrm{FB})$ evaluated the included studies based on a priori criteria, and extracted the relevant data. Publications in languages other than English were translated to English through Google Translate website (https://translate.google.com). Japanese language articles data were reviewed by a native speaker (TS). Korean language articles were also reviewed by a native speaker. The data included are shown in online supplement 3 .

\section{Assessment of methodological qualities of case reports and case series}

We applied a previously described tool, used in several systematic reviews with consistency among reviewers, to assess the methodological quality of case reports and case series $^{3-7}$ (see online supplements 3 and 4).

\section{Statistical analysis}

We compared patient characteristics, cyst type, surgical interventions and outcomes between cysts location (hepatic/extrahepatic/combined) and in multiple versus solitary cysts. Comparison was done using Pearson's $\mathrm{X}^{2}$ test. When the number of patients in any cell in a contingency table was under 5, we used Fisher's exact test. Two-tailed $p$ values were considered to be statistically significant when they were below 0.05 . Analysis was performed using Stata V.15 software (StataCorp, College Station, Texas, USA).

\section{RESULTS}

The flow diagram through the different phases of this systematic review is shown in online supplement 5 . We identified 9 studies that assessed the frequency and 72 case reports and case series with sufficient clinical data. Online supplements 3 and 7 show individual studies and granular information identified in this systematic review.

\section{Frequency of peribiliary cysts}

Online supplement 8 shows the frequency of peribiliary cysts in nine studies, and it ranged from $1 \%$ (liver transplant patients explant) to $100 \%$ (autopsy of patients with autosomal dominant polycystic liver disease (ADPLD)). In patients with autosomal dominant polycystic kidney disease (ADPKD), the disease was identified by contrast-enhanced CT (CECT) and magnetic resonance cholangiopancreatography (MRCP) in 54\% and 66\%, respectively. In a Japanese study assessing the frequency of these structures, $20 \%$ of 1000 autopsies showed mostly microscopic peribliary cysts. ${ }^{8}$

\section{Clinical characteristics of peribiliary cysts \\ Studies characteristics}

Most studies were reported from Japan (Japanese studies: 54/72 (75\%) —Japanese cases: 88/135 (65\%)). Online supplements 3 and 7 demonstrate individuals study characteristics. References of excluded studies and reasons for exclusion are found in online supplement 6 .

\section{Patient's characteristics}

Table 1 shows the main clinical characteristics of the identified 135 patients ( $80 \%$ males, median age 63 years, range (9-88)).

\section{Comorbidities}

Cirrhosis was the most frequent associated disease (52/135 patients-38\%), with alcohol being the most frequent aetiology $(24 / 52$ patients- $46 \%)$. Other associated conditions were reported such as portal hypertension, portal vein thrombosis, history of neoplasms, ADPKD, liver transplantation and primary sclerosing cholangitis (table 1). Hepatic, biliary or pancreatic neoplasms were reported in 23 patients $(17 \%)$ and were observed exclusively in patients with cirrhosis or in patients with multiple intrahepatic cysts (see online supplement $9)$. Hepatocellular carcinoma was the most frequent neoplasm (16 patients) followed by intraductal papillary neoplasm of the bile tract (4 patients). Other neoplasms such as gastric cancer or colon cancer were reported in 14 patients. No comorbid conditions were identified in $21 / 135(15 \%)$ of cases.

\section{Symptoms}

They were present in $70 \%$ of patients $(73 / 104)$, and were related to the associated disease (eg, symptoms of cirrhosis), to peribiliary cysts per se (eg, clinical manifestations of obstructive jaundice or cholangitis) or to both in $52 \%, 29 \%$ and $19 \%$, respectively. Asymptomatic incidental discovery characterised $30 \%(31 / 104)$ of patients.

\section{Diagnostic modalities of peribiliary cysts}

Online supplement 10 shows the diagnostic modalities of peribiliary cysts. CECT was diagnostic in 51 of 105 patients (48\%), drip infusion cholangiographic CT (DIC-CT) in 15 of 19 patients (79\%) and MRCP in 25 of 39 patients $(64 \%)$. Among 14 patients who were inaccurately diagnosed by MRCP, dilatation of the biliary tract was present in 11 patients and 3 of them had solitary cysts. Cholangioscopy performed in 12 patients demonstrated submucosal lesions in 7 of them $(58 \%)$, and intraductal ultrasound demonstrated cystic cavities in 3 of 4 of these cases $(75 \%)$. The central dot sign was reported in three patients on CECT.

\section{Initial misdiagnosis}

An alternative diagnosis was initially considered in 34 patients (cholangiocarcinoma in 25 patients). Other 
Table 1 Main characteristics of patients with peribiliary cysts

\begin{tabular}{|c|c|c|}
\hline \multirow[b]{2}{*}{ Characteristics } & \multirow{2}{*}{$\begin{array}{l}\begin{array}{l}\text { Available } \\
\text { values }\end{array} \\
\text { patients }\end{array}$} & \multirow{2}{*}{$\begin{array}{l}\text { Results } \\
\% \text { or median } \\
\text { (range) }\end{array}$} \\
\hline & & \\
\hline Age, years & 122 & $63(4-88)$ \\
\hline Males & 122 & $98 / 122(80 \%)$ \\
\hline Japanese patients & 135 & $88 / 135(65 \%)$ \\
\hline \multicolumn{3}{|l|}{$\begin{array}{l}\text { Associated conditions/ } \\
\text { diseases }^{*}\end{array}$} \\
\hline Cirrhosis (of all aetiologies) & 135 & $52 / 135(38 \%)$ \\
\hline Portal hypertension & 117 & $40 / 117(34 \%)$ \\
\hline Portal vein thrombosis & 117 & $12 / 117(10 \%)$ \\
\hline $\begin{array}{l}\text { Hepatic, biliary or pancreatic } \\
\text { neoplasms (\%) }\end{array}$ & 135 & $23 / 135(17 \%)$ \\
\hline ADPKD & 135 & 15/133 (11\%) \\
\hline Liver transplantation & 135 & $5 / 135(3 \%)$ \\
\hline Primary sclerosing cholangitis & 135 & $2 / 135(1.5 \%)$ \\
\hline $\begin{array}{l}\text { No associates conditions/ } \\
\text { diseases }\end{array}$ & 135 & $21 / 135(15 \%)$ \\
\hline \multicolumn{3}{|l|}{ Clinical manifestations } \\
\hline Asymptomatic patients & 104 & $31 / 104(30 \%)$ \\
\hline Symptomatic patients & 104 & $73 / 104(70 \%)$ \\
\hline $\begin{array}{l}\text { Symptoms related to associated } \\
\text { conditions/diseases }\end{array}$ & 73 & $38 / 73(52 \%)$ \\
\hline $\begin{array}{l}\text { Symptoms related to peribiliary } \\
\text { cyst(s) }\end{array}$ & 73 & $21 / 73(29 \%)$ \\
\hline $\begin{array}{l}\text { Symptoms related to associated } \\
\text { diseases and } \mathrm{PBC}(\mathrm{s})\end{array}$ & 73 & 14/73 (19\%) \\
\hline \multicolumn{3}{|l|}{$\begin{array}{l}\text { Complications of peribilary } \\
\text { cyst(s) }\end{array}$} \\
\hline $\begin{array}{l}\text { Dilated biliary tract (slight or } \\
\text { severe) }\end{array}$ & 126 & $47 / 126(36 \%)$ \\
\hline Obstructive jaundice & 126 & $18 / 126(14 \%)$ \\
\hline Cholangitis & 104 & $\begin{array}{l}13 / 104 \\
(12.5 \%)\end{array}$ \\
\hline \multicolumn{3}{|l|}{ Surgical interventions } \\
\hline Surgical interventions & 135 & $61 / 133(45 \%)$ \\
\hline $\begin{array}{l}\text { Therapeutic misadventures } \\
\text { related to incorrect diagnosis }\end{array}$ & 61 & 20/61 (33\%) \\
\hline
\end{tabular}

\section{Follow-up}

\begin{tabular}{|c|c|c|}
\hline Duration of follow-up, months & 40 & $18(1-92)$ \\
\hline $\begin{array}{l}\text { Increase in number and/or size } \\
\text { of cysts }\end{array}$ & 40 & $15 / 40(37.5 \%)$ \\
\hline \multicolumn{3}{|l|}{ Mortality } \\
\hline Overall mortality & 122 & 29/122 (24\%) \\
\hline $\begin{array}{l}\text { Death related to decompensated } \\
\text { cirrhosis }\end{array}$ & 21 & $17 / 21(81 \%)$ \\
\hline
\end{tabular}

*Some patients have more than one associated disease.

ADPKD, autosomal dominant polycystic kidney disease.
Table 2 Classification of peribiliary cysts based on their location along the biliary tract

\begin{tabular}{llcc}
\hline Location of cysts & $\begin{array}{l}\text { No of } \\
\text { patients }\end{array}$ & $\begin{array}{l}\text { Percentage } \\
\text { (\%) }\end{array}$ \\
\hline Type I & $\begin{array}{l}\text { Along intrahepatic biliary } \\
\text { tract }\end{array}$ & 118 & 87 \\
Type II & $\begin{array}{l}\text { Along extrahepatic biliary } \\
\text { tract }\end{array}$ & 9 & 7 \\
Type III & $\begin{array}{l}\text { Along intrahepatic and } \\
\text { extrahepatic biliary tract }\end{array}$ & 8 & 6 \\
Total & & 135 & 100 \\
\hline
\end{tabular}

suspected diseases were: hepatocellular carcinoma (one patient), liver metastasis (one patient), intraductal papillary mucinous neoplasm of the biliary tract (two patients), mucinous biliary cystadenoma (one patient), primary sclerosing cholangitis (two patients), Caroli disease (one patient) and choledochal cyst (one patient).

\section{Surgical intervention}

Surgical interventions were performed in 61 for different indications, 20 of which $(33 \%)$ were therapeutic misadventures for inaccurate diagnosis (left lateral segmentectomy (four patients), left lobectomy (eight patients), left lobectomy including the caudate lobe (two patients), left hepatectomy (two patients), extended left lobectomy (one patient), resection of hepatic segment VI (one patient), right hemihepatectomy (one patient) and duodenopancreatectomy (one patient)).

\section{Cysts characteristics}

Intrahepatic peribiliary cysts were found in $87 \%$, extrahepatic in $7 \%$ and both in $6 \%$ (table 2). The cysts were multiple in $90 \%$ and solitary in $10 \%$ of patients. The size of the cysts ranged from 1 to $55 \mathrm{~mm}$ in 92 patients with available data. In one patient, the cysts were microscopic and were associated with intraductal papillary neoplasm of the biliary tract. ${ }^{9}$

\section{Complications}

Complications related to peribiliary cysts were observed in 58 of 106 patients $(55 \%)$, and biliary tract dilatation, obstructive jaundice and cholangitis were the most reported ones (table 1). Other less frequent complications were noted in seven patients: hepatolithiasis (five patients), ${ }^{10-14}$ acute pancreatitis (one patient) ${ }^{15}$ and febrile peribiliary cysts infection (one patient). ${ }^{14}$ Some patients had more than one complication such as obstructive jaundice and cholangitis.

\section{Follow-up changes}

Data for 40 patients followed for a median period of 18 months (range: 1-92) were available, and an increase in size and/or number of cysts was reported in $40 \%$. Ten of these patients had cirrhosis, two had alcoholic hepatopathy, one had pancreatic cancer and two were without associated disease. 


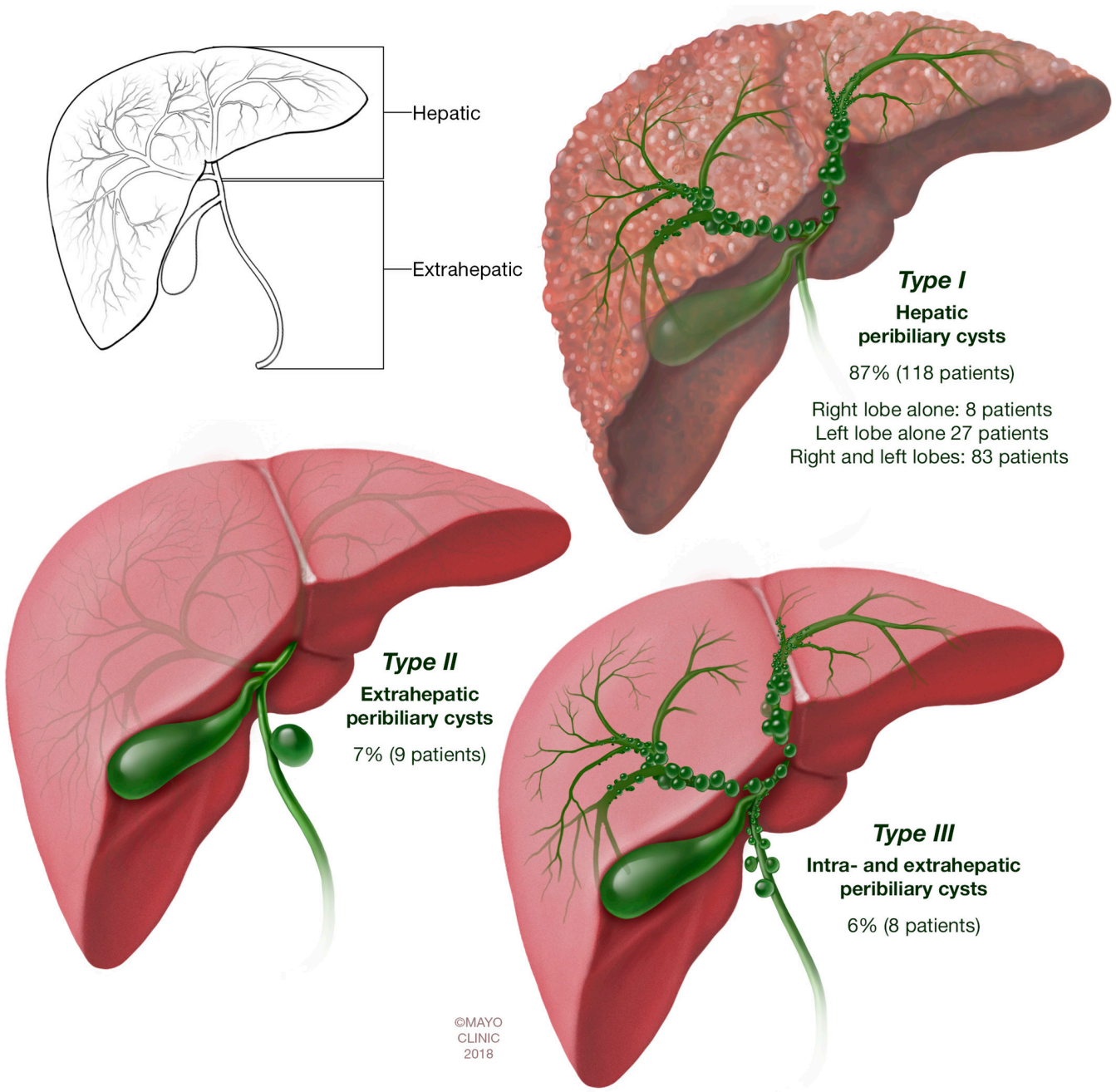

Figure 1 Proposal of a classification framework for peribiliary cysts. When the hepatic bile duct bifurcation delineates two hepatobiliary segments: hepatic and extrahepatic, we identify the following types: type I: hepatic, type II: extrahepatic, type III: mixed hepatic and extrahepatic.

\section{Mortality}

Death was reported in 29 of 122 patients (mortality rate $24 \%$ ), and postmortem exam was performed in 27 patients. Among patients with reported cause of death (21 patients), decompensated cirrhosis was the most frequent culprit $(17 / 21 \%-81 \%)$. The other causes of mortality were: acute respiratory distress syndrome in a patient with cirrhosis ${ }^{16}$; recurrent cholangitis after duodenopancreatectomy for intraductal papillary mucinous neoplasm of the pancreas in one patient ${ }^{17}$ and pneumonia in a kidney transplant patient ${ }^{18}$ and in a patient with acute myeloid leukaemia. ${ }^{19}$

\section{ASSESSMENT OF METHODOLOGICAL QUALITIES OF INCLUDED STUDIES}

As shown in online supplement $11,67 \%$ studies had good, $23 \%$ had moderate and $10 \%$ had ow methodological quality. Agreement between the two reviewers in assessing the methodological quality was evaluated with inter-rater reliability of $93 \%$.

\section{PROPOSAL OF A CLASSIFICATION FRAMEWORK FOR PERIBILIARY CYSTS}

When the hepatic bile duct bifurcation delineates two hepatobiliary segments: hepatic and extrahepatic, we identify the following types: type I: hepatic, type II: extrahepatic, type III: mixed hepatic and extrahepatic (table 2 and figure 1). Characteristics and implications of the lesions, as they relate to the anatomic location are shown in online supplement 12. Extrahepatic cysts, compared with other cysts, were more frequent in females, solitary with no associated cirrhosis or portal hypertension, presenting frequently with obstructive jaundice, more difficult to diagnose by imaging modalities and required more surgical interventions (all $\mathrm{p}<0.05$ ) (table 3 ). There was a trend of better prognosis in extrahepatic cysts compared with other cysts (mortality rate: $11 \%$ vs $25 \%, \mathrm{p}=0.68)$. The comparison between multiple and solitary cysts is shown in online supplement 13 . Solitary cysts share some of the extrahepatic cysts characteristics: more frequent in females, less association with cirrhosis and portal hypertension and more difficult to diagnose 
Table 3 Comparison between hepatic and hepatic/extrahepatic cysts vs extrahepatic cysts

\begin{tabular}{|c|c|c|c|}
\hline Characteristics & $\begin{array}{l}\text { Type I and III hepatic and } \\
\text { combined } \\
126 \text { patients Age } 63 \text { (4-88)* }\end{array}$ & $\begin{array}{l}\text { Type II extrahepatic } \\
9 \text { patients Age } 61 \text { (43-79 years)* }\end{array}$ & $P$ values \\
\hline Males (\%) & $96 / 113(85 \%)$ & $2 / 9(22 \%)$ & 0.0001 \\
\hline Japanese patients (\%) & $80 / 126(63 \%)$ & $5 / 9(55 \%)$ & 0.7257 \\
\hline Associated diseases (\%) & $111 / 126(88 \%)$ & $6 / 9(66 \%)$ & 0.1003 \\
\hline Cirrhosis (\%) & $52 / 126(41 \%)$ & $0 / 9(0 \%)$ & 0.0126 \\
\hline Portal hypertension (\%) & $40 / 108(37 \%)$ & $0 / 9(0 \%)$ & 0.0269 \\
\hline Hepatic, biliary or pancreatic neoplasms (\%) & 23/126 (18\%) & $0 / 9(0 \%)$ & 0.3590 \\
\hline Incorrect diagnosis by imaging modalities (\%) & 42/109 (38\%) & $5 / 6(83 \%)$ & 0.0409 \\
\hline Solitary cysts (\%) & $4 / 126(3 \%)$ & $9 / 9(100 \%)$ & 0.0001 \\
\hline Dilated biliary tract (\%) & $43 / 117(37 \%)$ & $4 / 9(44 \%)$ & 0.7263 \\
\hline Obstructive jaundice (\%) & $14 / 117(12 \%)$ & $4 / 9(44 \%)$ & 0.0237 \\
\hline Cholangitis (\%) & $13 / 95(14 \%)$ & $1 / 9(11 \%)$ & 1.0000 \\
\hline Surgical interventions (\%) & $53 / 126(42 \%)$ & $8 / 9(89 \%)$ & 0.0111 \\
\hline Therapeutic misadventures (\%) & $19 / 53(36 \%)$ & $1 / 8(12.5)$ & 0.2532 \\
\hline Mortality rate (\%) & $28 / 113(25 \%)$ & $1 / 9(11 \%)$ & 0.6846 \\
\hline
\end{tabular}

*Median age and range.

by imaging modalities (all $\mathrm{p}<0.05)$. There was a trend of better prognosis in solitary cysts compared with multiple cysts (mortality rate: $8 \%$ vs $26 \%, \mathrm{p}=0.19$ ).

\section{GENERALISABILITY OF THE RESULTS}

The presence of selection bias favouring the report of more severe cases limits the generalisability of all results of this review to patients with peribiliary cysts. However, the majority of included studies had a good methodological quality, making their results applicable in the appropriate context, and they were not restricted to a certain ethnicity.

\section{DISCUSSION}

Peribiliary cysts result from cystic dilatation of the extramural peribiliary glands located on both sides of the intrahepatic and extrahepatic bile ducts. ${ }^{20}$ The disease was first described in Japan by Nakanuma et $a l^{21}$ in 1984 as an incidental finding in eight autopsy cases. Grossly, they are often multiple, featuring thin transparent walls and serous contents (figure 2). Histologically, the cysts are associated with dilated peribiliary glands, suggesting variable developmental stages of the process. ${ }^{22}$ The epithelial lining is most often flat and attenuated, but resembles the epithelial lining of peribiliary glands. ${ }^{23}$

Several names has been given to the disease in the literature such as 'multiple cysts in the hepatic hilum', 'hepatic cysts of periductal gland origin', 'mucinous hamartoma of the biliary system', 'multiple hilar cysts', 'Nakanuma disease', 'hepatic peribiliary cysts' and 'peribiliary cysts' ${ }^{23}$ The last two names are preferred by most authors, and are the most widely used.
The disease was prevalent in studies designed to examine its frequency especially in patients with cirrhosis, ADPKD and ADPLD, and cysts were mostly microscopic and asymptomatic. In this systematic review, we identified 72 reports with 135 cases from 10 countries, spanning a period of 33 years.

Almost two-thirds of cases emanate from Japan. An awareness publication bias could be behind this observation, since the disease was first described in Japan, and under-reporting due to clinical unawareness in other parts of the world may account for this trend. For example, the two French reports in this systematic review ${ }^{24} 25$ have been published by the same group from Clermont-Ferrand, while no reports have been published from other parts of France. Other factors, such as ethnic and environmental determinants, might be in play.

We found higher male gender predilection, which may be partially related to higher alcohol consumption. ${ }^{26}$ Of the 33 patients with alcoholic liver disease, identified in this review, $88 \%$ were male. Other possible hormonal, genetic or acquired factors may be in play.

Although the pathogenesis remains unclear, two scenarios are considered. ${ }^{27}$ One is congenital or developmental, and is associated with fibrocystic diseases such as ADPKD or ADPLD. The other is secondary to alcohol use, cirrhosis, portal hypertension and portal vein thrombosis. ${ }^{28}{ }^{29}$ In this systematic review, $15 \%$ of the cases were idiopathic without any recognised associated condition.

Chronic alcohol may injure the peribiliary glands, and among consecutive autopsy cases of chronic alcoholics in a Japanese study, cysts were found in $14 \%$, and their frequency correlated with the degree of alcohol-related 

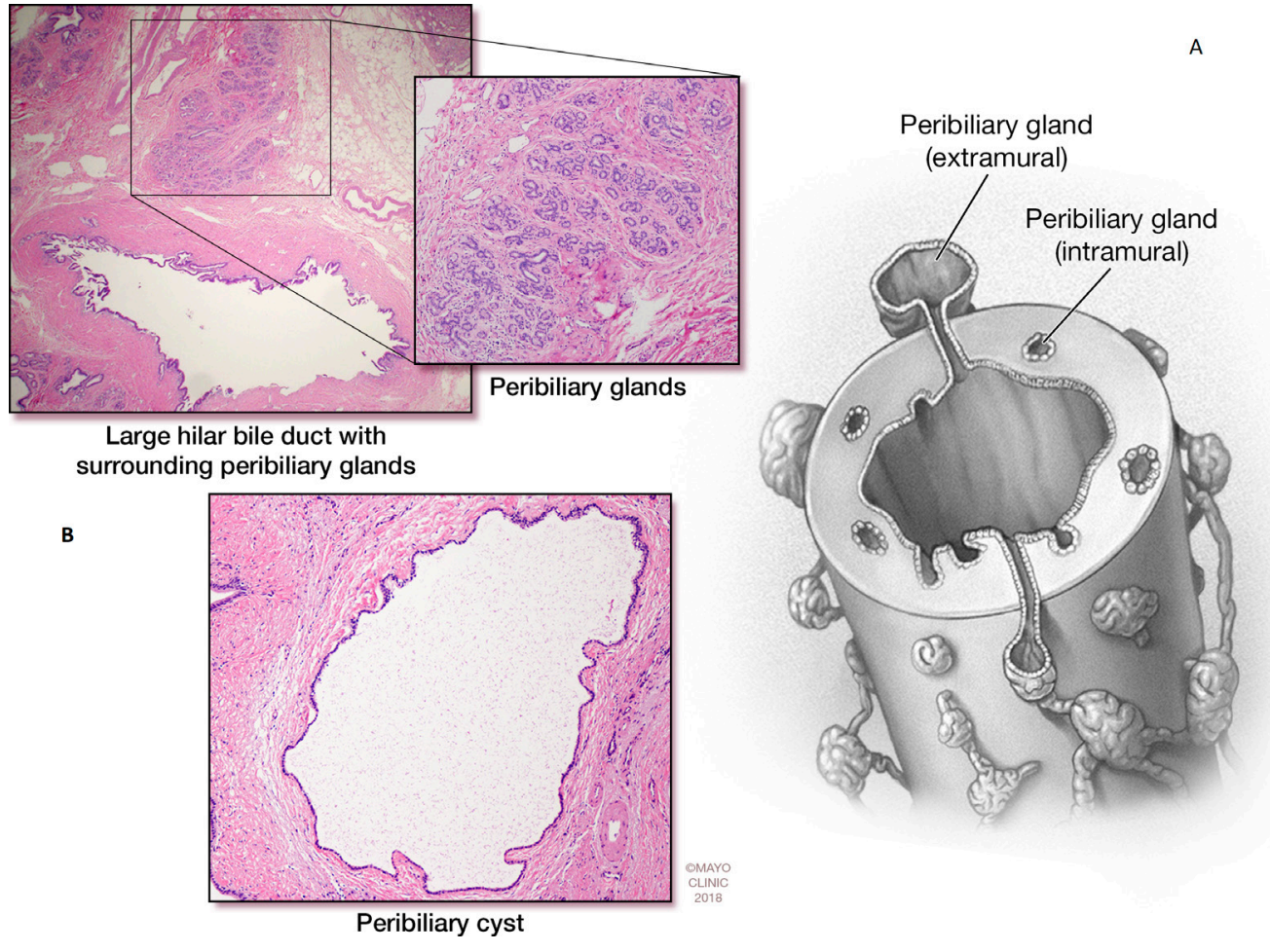

Figure 2 (A) Schematic representation of peribiliary glands, and histology. (B) Histology of a peribiliary cyst.

hepatic fibrosis. ${ }^{30}$ In this systematic review, alcoholic liver disease with or without cirrhosis was reported in $28 \% .{ }^{3132}$

Another interesting observation is the neoplastic associations, with $20 \%$ of patients in this review harbouring hepatic, biliary or pancreatic neoplasms. Hepatocellular carcinoma was the most reported neoplasm and occurred in patients with cirrhosis. Peribiliary cysts may have been the origin of the biliary neoplasms encountered in this review. ${ }^{33}$ Sato et al reported peribiliary glands epithelial changes in almost $10 \%$ of cases in an autopsy study, ${ }^{34}$ and such changes may be precursors of intraductal papillary neoplasm of the bile duct, as well as cholangiocarcinoma, although their clinical significance remains unclear. ${ }^{35}$

This systematic review reveals that establishing a correct diagnosis of peribiliary cysts is essential to avoid therapeutic misadventures which were observed in one-third of patients. Cholangiocarcinoma was the most frequent suspected disease in difficult-to-diagnose cases. Considering the prevalence of these lesions in patients with cirrhosis, it is critical to accurately establish the diagnosis to prevent delisting of an otherwise appropriate liver transplantation candidate. ${ }^{36}$ In addition, it is important to differentiate peribiliary cysts from other conditions such as dilated bile ducts, intraductal papillary mucinous neoplasm of the bile duct, cystic metastasis of a malignancy, primary sclerosing cholangitis and Caroli disease.

Awareness of the disease, especially in patients with cirrhosis, is the first step towards the accurate diagnosis. CECT and MRCP are good imaging modalities for identifying the cysts. DIC-CT, MRI with administration of gadoxetic acid (Eovist in the USA and Primovist in Canada, Europe and Asia, Bayer Healthcare Pharmaceuticals,
Wayne, New Jersey, USA), or ERCP when indicated, are useful to establish presence or absence of biliary luminal communication. DIC-CT may have a limited role in patients with decompensated cirrhosis since it requires normal hepatic function to clearly delineate the bile ducts and is not available in some countries. MRCP was less accurate than DIC-CT for the diagnosis of peribiliary cysts in this review ( $64 \%$ vs $79 \%$, respectively; $\mathrm{p}=0.37$ ). Cholangioscopy may raise suspicion of the disease by visualising submucosal lesions when other imaging modalities were not diagnostic, and intraductal ultrasound could be helpful. We propose an algorithm of different imaging modalities for the diagnosis of peribiliary cysts (figure 3). Further studies are needed to determine the diagnostic accuracy of combined imaging modalities in challenging cases.

Interestingly, progression of size and/or number of these structures may serve as a marker for worsening liver disease,${ }^{28}$ and this was observed in a third of patients with available data.

We found that peribiliary cysts were solitary in $10 \%$ of cases and located along the extrahepatic biliary tract (either alone or in association with intrahepatic location) in $13 \%$ of cases. We propose a novel classification of peribiliary cysts, based on biliary distribution, in order to emphasise these two aspects of the disease, and to study their different characteristics according to their anatomic location. We observed that solitary cysts, mostly extrahepatic, have special characteristics, and warrant a distinct approach.

This review has several inherent and unavoidable limitations. First, it is based on case reports and case series with high likelihood of associated bias. However, evidence 


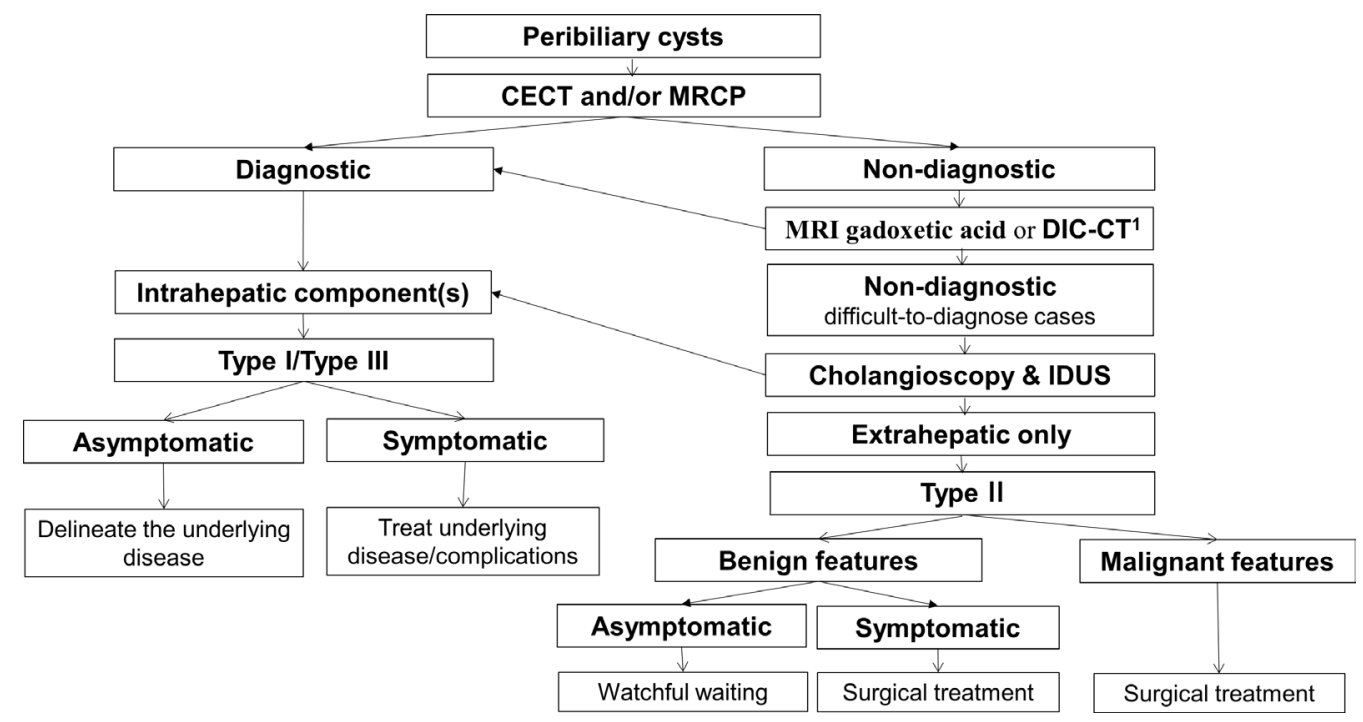

Figure 3 Proposal of algorithm to approach and evaluate peribiliary cysts. *DIC-CT is not available in some countries and could be replaced by MRI gadoxetic acid. CECT, contrast-enhanced CT; DIC-CT, drip infusion cholangiographic CT; IDUS, intraductal ultrasound; MRCP, magnetic resonance cholangiopancreatography.

from case report and case series become more significant when higher evidence is absent. ${ }^{5}$ Second, we were not able to reflect the natural history, and a publication bias favouring the report of most severe cases is certain. Indeed, the disease was frequent in the studies incepted to assess its frequency, and most cysts were asymptomatic and microscopic. Third, missing data in some reports precluded obtaining complete clinical and prognostic information. However, we were able to reveal some of the epidemiological, clinical, diagnostic and prognostic aspects that have been identified in this disease. Fourth, the diagnostic accuracy of different imaging modalities was not stated in all studies. However, two reviewers evaluated this accuracy, when needed, based on reported results, and disagreements were resolved by discussion. Lastly, our proposed tool for quality assessment of case reports and case series has not been validated, although it was derived from a commonly used instrument and was previously applied with good consistency.

To our knowledge, this is the first systematic review that attempts to synthesise the evidence about peribiliary cysts. This synthesis followed a priori developed protocol and included evaluation of multiple databases by pairs of independent reviewers. More studies are needed to further delineate the pathogenesis of the disease, its relationship with biliary neoplasia, the diagnostic accuracy of combined imaging modalities in challenging cases and to evaluate the utility of the proposed classification.

\section{CONCLUSION}

Although rarely studied in the literature, pribiliary cysts were frequent in studies designed to evaluate their prevalence, and were mostly asymptomatic. Inaccurate diagnosis, therapeutic misadventures, cysts progression and cysts-related complications are frequent. In a novel classification framework based on location, extrahepatic peribiliary cysts appear to have distinct characteristics and require a special approach for diagnosis and management.

Acknowledgements The authors would like to thank Dr Chul Kim (Division of Hematology and Oncology, Department of Medicine, Georgetown University, Washington, DC) for revising the translation of the Korean papers included in this review, to Dr Kotaro Yoshida (Department of Radiology, Kanazawa University Graduate School of Medical Science, Kanazawa, Japan) for his valuable information on the actual status of DIC-CT in Japan and to Mr. Larry Prokop for excellent librarian assistance.

Contributors All authors contributed to the study concept and design, analysis and interpretation of data, drafting of the manuscript, critical revision of the manuscript for important intellectual content and statistical analysis. All authors approved the final manuscript.

Funding This research received no specific grant from any funding agency in the public, commercial or not-for-profit sectors.

Competing interests None declared.

Patient consent Not required.

Ethics approval The IRB exempted this systematic review and pooled anaylsis from IRB approval as it did not involve new research on new human subjects.

Provenance and peer review Not commissioned; externally peer reviewed.

Data sharing statement Additional data are available in the online supplements.

Open Access This is an Open Access article distributed in accordance with the Creative Commons Attribution Non Commercial (CC BY-NC 4.0) license, which permits others to distribute, remix, adapt, build upon this work non-commercially, and license their derivative works on different terms, provided the original work is properly cited and the use is non-commercial. See: http://creativecommons.org/ licenses/by-nc/4.0/

(C) Article author(s) (or their employer(s) unless otherwise stated in the text of the article) 2018. All rights reserved. No commercial use is permitted unless otherwise expressly granted.

\section{REFERENCES}

1. Tamilarasan AG, Yang J, Lee AU. Peribiliary cysts presenting as primary sclerosing cholangitis. Clin Gastroenterol Hepatol 2018

2. Díaz Alcázar MDM, Martín-Lagos Maldonado A, Ruiz Escolano E. Complicated peribiliary cysts in patient without any prior liver disease. Rev Esp Enferm Dig 2018;110:128. 
3. Bazerbachi F, Sawas T, Vargas EJ, et al. Metal stents versus plastic stents for the management of pancreatic walled-off necrosis: a systematic review and meta-analysis. Gastrointest Endosc 2018;87:30-42.

4. Bazerbachi F, Haffar S, Hussain MT, et al. Systematic review of acute pancreatitis associated with interferon- $\alpha$ or pegylated interferon- $\alpha$ : Possible or definitive causation? Pancreatology 2017.

5. Murad MH, Sultan S, Haffar S, et al. Methodological quality and synthesis of case series and case reports. BMJ Evid Based Med 2018;23:60-3

6. Bazerbachi F, Haffar S, Szarka LA, et al. Secretory diarrhea and hypokalemia associated with colonic pseudo-obstruction: A case study and systematic analysis of the literature. Neurogastroenterol Motil 2017;29:e13120.

7. Haffar S, Bazerbachi F, Prokop L, et al. Frequency and prognosis of acute pancreatitis associated with fulminant or non-fulminant acute hepatitis A: A systematic review. Pancreatology 2017;17:166-75.

8. Terada T, Nakanuma Y. Pathological observations of intrahepatic peribiliary glands in 1,000 consecutive autopsy livers. III. Survey of necroinflammation and cystic dilatation. Hepatology 1990;12:1229-33.

9. Nakanishi Y, Nakanuma Y, Ohara M, et al. Intraductal papillary neoplasm arising from peribiliary glands connecting with the inferior branch of the bile duct of the anterior segment of the liver. Pathol Int 2011;61:773-7.

10. Kai K, Eguchi Y, Kumagai T, et al. An autopsy case of obstructive jaundice due to hepatic multiple peribiliary cysts accompanying hepatolithiasis. Hepatol Res 2008;38:211-6.

11. Kolodziejski TR, Safadi BY, Nakanuma Y, et al. Bile duct cysts in a patient with autosomal dominant polycystic kidney disease. Gastrointest Endosc 2004;59:140-2.

12. Matsukura M, Chida T, Kageyama F, et al. A case of intrahepatic choledochal stone and peribiliary cysts with bile duct stricture. Journal of Hamamatsu Medical Center 2010;4.

13. Terada T, Matsushita $\mathrm{H}$, Tashiro J, et al. Cholesterol hepatolithiasis with peribiliary cysts. Pathol Int 2003;53:716-20.

14. Teramoto A, Nakamatsu G, Shimizu S, et al. A case of peribiliary cyst infection due to hepatolithiasis. Am J Gastroenterol 2015;110:S51-S2.

15. Ueki Y, Mori T, Tominaga $\mathrm{Y}$, et al. [A case of simple cyst derived from the common bile duct; undiscriminated from malignant lesion]. Nihon Naika Gakkai Zasshi 1987;76:76.

16. Stevens W, Harford W, Lee E. Obstructive jaundice due to multiple hepatic peribiliary cysts. Am J Gastroenterol 1996;91:155-7.

17. Sato Y, Mukai M, Sasaki M, et al. Intraductal papillary-mucinous neoplasm of the pancreas associated with polycystic liver and kidney disease. Pathol Int 2009;59:201-4.

18. Wanless IR, Zahradnik J, Heathcote EJ. Hepatic cysts of periductal gland origin presenting as obstructive jaundice. Gastroenterology 1987:93:894-8.
19. Takahashi H, Miwa S, Nomoto K, et al. Peribiliary cyst of common bile duct: possible cause of refractory jaundice. Pathol Int 2009;59:692-3.

20. Kudo M. Hepatic peribiliary cysts: clinically harmless disease with potential risk due to gradual increase in size and number. $J$ Gastroenterol 2001;36:286-8.

21. Nakanuma Y, Kurumaya H, Ohta G. Multiple cysts in the hepatic hilum and their pathogenesis. Virchows Arch A Pathol Anat Histopathol 1984;404:341-50.

22. Hubscher SG, Burt AD, Portmann BC, et al. MacSween's pathology of the liver E-Book: Elsevier Health Sciences, 2011.

23. Fujioka Y, Kawamura N, Tanaka S, et al. Multiple hilar cysts of the liver in patients with alcoholic cirrhosis: report of three cases. $J$ Gastroenterol Hepatol 1997;12:137-43.

24. Da Ines D, Essamet W, Montoriol PF. Peribiliary cysts. Hepatology 2011;54:2272-3.

25. Montoriol PF, Poincloux L, Petitcolin V, et al. Peribiliary cysts mistaken for a biliary dilatation in a cirrhosis patient. Clin Res Hepatol Gastroenterol 2012;36:e93-e95.

26. Shimizu I, Kamochi M, Yoshikawa H, et al. Gender difference in alcoholic liver disease. InTech: Trends in Alcoholic Liver Disease Research-Clinical and Scientific Aspects, 2012.

27. Nakanuma Y. Pathology of the bile duct: Springer, 2017.

28. Nakanuma Y. Peribiliary cysts have at least two different pathogeneses. J Gastroenterol 2004;39:407-8.

29. Kozaka K, Osamu M. Radiological approaches to biliary diseases with pancreatic counterparts. Biliary diseases with pancreatic counterparts: a new disease concept: Nova Science Publishers, Inc, 2017:217-33.

30. Matsubara T, Sato Y, Igarashi S, et al. Alcohol-related injury to peribiliary glands is a cause of peribiliary cysts: based on analysis of clinical and autopsy cases. J Clin Gastroenterol 2014;48:153-9.

31. Ohta $\mathrm{H}, \mathrm{Baba} Y$, Ishikawa $\mathrm{T}$, et al. A clinical evaluation of hepatic peribiliary cysts. Kanzo 2003;44:58-65.

32. Kozuki A, Shima Y, Sumiyoshi T. A resected case of hepatic peribiliary cysts difficult to distinguish from intrahepatic cholangiocarcinoma. Tan to Sui 2012;26:604-9.

33. Zen Y, Amarapurkar AD, Portmann BC. Intraductal tubulopapillary neoplasm of the bile duct: potential origin from peribiliary cysts. Hum Pathol 2012;43:440-5.

34. Sato $\mathrm{Y}$, Harada K, Sasaki M, et al. Cystic and micropapillary epithelial changes of peribiliary glands might represent a precursor lesion of biliary epithelial neoplasms. Virchows Arch 2014;464:157-63.

35. Sato Y. Cystic and micropapillary neoplasm of peribiliary glands: its perspective to cholangiocarcinogenesis. Springer: Pathology of the Bile Duct, 2017:177-88.

36. Lim J, Nissen NN, McPhaul C, et al. Peribiliary hepatic cysts presenting as hilar cholangiocarcinoma in a patient with end-stage liver disease. J Surg Case Rep 2016;8:10. 